ASIMETRIS: JURNAL PENDIDIKAN MATEMATIKA DAN SAINS

$$
\text { p-ISSN } 2721 \text { - 8724, e-ISSN } 2722 \text { - } 0214
$$

Website Jurnal: http://journal.umuslim.ac.id/index.php/asm/

\begin{aligned} & Info Artikel: Direvisi pada 16 Oktober 2021 \\ & Disubmit pada 10 Oktober 2021 Diterima pada 20 Oktober 2021 \\ & Direview pada 15 Oktober 2021 Tersedia secara daring pada 28 Oktober 2021 \\ & \hline\end{aligned}

\title{
PENGARUH PENERAPAN MODEL PEMBELAJARAN ROUND CLUB PADA MATERI MATRIKS
}

\author{
Riska1, Siti Khaulah² \\ 1,2 Pendidikan Matematika Universitas Almuslim Bireuen, Aceh, Indonesia \\ Alamat email: riska.mat@gmail.com
}

\begin{abstract}
ABSTRAK. Penelitian ini bertujuan untuk mengetahui pengaruh Penerapan Model Pembelajaran Round Club Pada Materi Matriks di Kelas XI SMA Negeri 1 Peusangan Siblah Krueng. Populasi penelitian ini adalah seluruh siswa kelas XI IPA 1 yang terdirri dari 30 orang siswa. Penelitian ini menggunakan pendekatan kuantitatif dengan jenis penelitian eksperimen. Desain penelitian yang tepat untuk dilaksanakan dalam penelitian ini yaitu One Group Pretest Postest Desain. Data dianalisis dengan data korelasi Product Moment. Hasil analisis diperoleh rhitung $>$ rtabel yaitu 0,980 >0,361. Hal ini berarti terdapat korelasi yang positif antara sebelum dan sesudah dilaksanakan model pembelajaran Round Club sesuai dengan interpretasi koefisian korelasi menunjukkan interpretasi yang sangat kuat, serta diperoleh thitung $>$ ttabel yaitu $8,240>2,048$. Hal ini menunjukkan bahwa ada pengaruh model pembelajaran Round Club terhadap hasil belajar siswa pada materi matriks di kelas XI SMA Negeri 1 Peusangan Siblah Kueng. Hasil pengamatan aktivitas proses belajar mengajar yaitu aktivitas guru dan aktivitas siswa pada pembelajaran Round Club menunjukkan bahwa ketaraf yang lebih baik.
\end{abstract}

Kata Kunci: Matriks, Round Club

ABSTRAK. Low student learning outcomes are a serious problem in learning mathematics, especially in solving problems related to the application and understanding of concepts. To solve this problem, the researcher conducted a study using the Round Club learning model. This study aims to determine the effect of the Application of the Round Club Learning Model on the Matrix Material in Class XI of SMA Negeri 1 Peusangan Siblah Krueng. The population of this study were all students of class XI IPA 1 which consisted of 30 students. This study uses a quantitative approach to the type of experimental research. The right research design to be carried out in this study is One Group Pretest Postest Design. Data were analyzed with Product Moment correlation data. The results of the analysis obtained rcount> rtable, namely 0.980>0.361. This means that there is a positive correlation between before and after the Round Club learning model is implemented according to the interpretation of the correlation coefficient which shows a very strong interpretation, and it is obtained that tcount> ttable is 8.240> 2.048. This shows that there is an effect of the Round Club learning model on student learning outcomes on matrix material in class XI SMA Negeri 1 Peusangan Siblah Kueng. The results of observations of learning activities which include teacher and student activities in both lessons show that the level is better.

Keyword: Matriks; Round Club

\section{PENDAHULUAN}

Pendidikan merupakan suatu usaha pengembangan tingkat kemampuan seseorang dalam memahami suatu pembelajaran yang dilakukan secara sistematis dan berjenjang melalui pembentukan kecakapan-kecakapan fundamental secara intelektual dan emosional. Menurut Mulyasa (2007) pada dasarnya pendidikan meruapakan suatu proses yang membantu manusia dalam pengembangan diri sehingga dapat menjalani semua perubahan dari permasalahan dengan kreatif dan sikap terbuka tanpa kehilangan identitas terhadap dirinya sendiri. Seiring perkembangan ilmu pengetahuan dan teknologi yang semakin pesat dari waktu ke waktu menyebabkan adanya 
persaingan dalam berbagai bidang kehidupan, salah satu diantaranya adalah bidang pendidikan. Untuk mencetak Sumber Daya Manusia (SDM) yang berkualitas dan terampil dibutuhkan adanya peningkatan mutu pendidikan. Berbagai upaya telah dilakukan para pendidik untuk mengembangkan kemampuan siswa dalam belajar pada seluruh mata pelajaran umumnya, dan khususnya pada pelajaran matematika.

Matematika adalah bagian salah satu cabang ilmu pengetahuan yang dapat meningkatkan kualitas SDM. Dengan berbagai peranannya dalam kehidupan menjadikan matematika sebagai ilmu yang sangat penting untuk dipelajari. Rahman (2010) menyatakan bahwa pembelajaran matematika memiliki manfaat sebagai salah satu sarana untuk mengembangkan kemampuan berpikir kritis, logis, kreatif, analitis, sistematis, dan bekerja sama yang diperlukan siswa dalam kehidupan modern agar dapat memiliki kemampuan mengumpulkan informasi, mengelola, dan memanfaatkan informasi tersebut dalam dunia yang terus berkembang. Kemampuan berpikir dapat dikembangkan melalui belajar matematika dikarenakan konsep-konsepnya yang memiliki struktur dan keterkaitan yang kuat dan jelas sehingga memungkinkan siswa terbiasa dan terampil dalam mengggunakan kemampuan berpikirnya. Hal inilah yang menjadi alasan pentingnya mata pelajaran matematika diberikan kepada semua peserta didik mulai dari sekolah dasar hingga jenjang pendidikan yang lebih tinggi.

Berdasarkan hasil observasi di SMA Negeri 1 Peusangan Siblah Krueng melalui wawancara yang telah dilakukan dengan salah satu guru matematika matematika lbu Khairani, S.Pd bahwa siswa di sana masih kurang optimal dalam penguasaan materi matriks. Banyak siswa yang mengeluh akan susahnya memahami materi matriks. Mereka masih sering tertukar tukar ketika mengoperasikan baris dan kolom pada materi matriks. Ketika siswa tidak bisa menyelesaikan permasalahan tersebut peneliti menerapkan model pembelajaran yang lebih menilai keaktifan siswa dalam pembelajaran, sehingga tujuan akhir yang diperoleh siswa dalam belajar lebih dominan dari pada guru dalam mengajar. Guru sebagai pengajar tidak aktif dalam mengajar didepan kelas, tetapi membantu menciptakan suasana yang nyaman serta memberikan bimbingan agar siswa dapat mengembangkan potensi dan kreatifitasnya dalam kegiatan belajar.

Kendala yang terjadi dalam proses pembelajaran selama ini, diperlukan upaya dengan menerapkan model pembelajaran matematika yang dapat membuat siswa lebih aktif dalam megikuti proses pembelajaran sehinggam pembelajaran yang bersifat konvensional yang terpusat pada guru dapat berubah menjadi berpusat kepada siswa. Salah satunya berupa pembelajaran kooperatif yang merupakan pembelajaran dalam bentuk kelompok untuk menyelesaikan suatu persoalan dan mencapai tujuan bersama, diantaranya adalah model pembelajaran Round Club.

Menurut Anita (2010) Model Pembelajaran Round Club merupakan suatu kegiatan pembelajaran kooperatif dengan cara berkelompok sehingga dapat bekerja sama dan saling membantu mengkontruksi konsep penyelesaian persoalan atau inkuiri. Berdasarkan penelitian yang dilakukan Ramadhani, dkk (2017) menyimpulkan bahwa terdapat peningkatan hasil belajar siswa dengan menggunakan model pembelajaran dengan model Round Club.

Berdasarkan uraian diatas, maka dipandang perlu untuk meneliti dengan judul "Penerapan Model Pembelajaran Round Club Pada Materi Matriks di Kelas XI SMA Negeri 1 Peusangan Siblah Krueng".

\section{METODE PENELITIAN}

Berdasarkan jenis penelitian yang diterapkan, maka peneliti memilih salah satu desain penelitian yang tepat untuk dilaksanakan dalam penelitian ini yaitu One Group Pretest Postest Desain (Sugiyono, 2017). Rancangan ini hanya menggunakan satu kelas saja, tidak ada kelas kontrol atau kelas pembanding. 
Perbedaannya yaitu terletak pada tes awal yang diberikan sebelum dimulainya inrtuksi atau perlakuan. Sehingga terdapat dua tes yaitu $\mathrm{O}_{1}$ adalah tes awal dan $\mathrm{O}_{2}$ adalah tes akhir serta $\mathrm{X}$ digunakan sebagai lambang perlakuan pada rancangan.

Penelitian ini dilakukan di SMA Negeri 1 Peusangan Siblah Krueng Kabupaten Bireuen tahun pelajaran 2020/2021 di kelas XI. Waktu penelitian adalah pada semester ganjil. Populasi dalam penelitian ini adalah seluruh siswa kelas XI SMA Negeri 1 Peusangan Siblah Krueng Kabupaten Bireuen tahun pelajaran 2020/2021. Sedangkan yang menjadi sampel dalam penelitian ini adalah siswa kelas XI IPA 1 yang dipilih secara random.

Pengumpulan data dalam penelitian ini dilakukan melalui test yang dilakukan sebanyak dua kali, yaitu tes awal (pre-test) dan tes akhir (post-test), observasi terhadap pembelajaran yang dilaksanakan.

Data yang dikumpul akan diolah dengan menggunakan uji statistik yang sesuai. Adapun langkah pengolahan data dalam penelitian ini adalah menentukan variabel penelitian, dalam penelitian ini terdapat dua vaiabel yaitu variabel $X$ dan $Y$. Variabel $X$ adalah nilai pe-test siswa, sedangkan variable $Y$ adalah nilai post-test siswa setelah menggunakan model pembelajaran Round Club.

Rumus uji koelasi product moment (Margono,2007:209):

$r_{x y}=\frac{n \sum x_{i} y_{i}-\left(\sum x_{i}\right)\left(\Sigma y_{i}\right)}{\sqrt{\left\{n \sum x_{i}^{2}-\left(\sum x_{i}\right)^{2}\right\}\left\{n \sum y_{i}^{2}-\left(\sum y_{i}\right)^{2}\right\}}}$

Keterangan :

$r_{x y} \quad$ : koefisien korelasi

$\mathrm{n} \quad$ : jumlah sampel penelitian

$X \quad$ : variabel test sebelum pembelajaran dengan Round Club

Y $\quad$ : variabel test sesudah pembelajaran dengan Round Club

\section{HASIL PENELITIAN DAN PEMBAHASAN}

Dalam bab ini penulis meguraikan tentang hasil penelitian yang dilaksanakan di SMA Negeri 1 Peusangan Siblah Krueng pada tanggal 21 Juli 2020 yaitu pada Kelas XI IPA 1 yang berjumlah 30 orang siswa guna memperoleh data yang diperlukan. Jadwal kegiatan ini disajikan dalam tabel beriku:

Tabel 3.1. Jadwal pelaksanaan penelitian

\begin{tabular}{|c|c|c|c|}
\hline Kegiatan & Kelas & Hari/Tanggal & $\begin{array}{c}\text { Jam } \\
\text { Belajar }\end{array}$ \\
\hline Tes awal & $\begin{array}{l}\text { Round } \\
\text { Club }\end{array}$ & $\begin{array}{c}\text { Senin, 20 Juli } \\
2020\end{array}$ & $1-2$ \\
\hline $\begin{array}{l}\text { Pembelajaran } \\
\text { (Pertemuan.1) }\end{array}$ & $\begin{array}{l}\text { Round } \\
\text { Club }\end{array}$ & $\begin{array}{l}\text { Selasa, } 21 \text { Juli } \\
2020\end{array}$ & $3-4$ \\
\hline $\begin{array}{l}\text { Pembelajaran } \\
\text { (Pertemuan.2) }\end{array}$ & $\begin{array}{l}\text { Round } \\
\text { Club }\end{array}$ & $\begin{array}{c}\text { Kamis, } 23 \text { Juli } \\
2020\end{array}$ & $3-4$ \\
\hline Tes akhir & $\begin{array}{c}\text { Round } \\
\text { Club }\end{array}$ & $\begin{array}{c}\text { Sabtu, 25 Juli } \\
2020\end{array}$ & $5-6$ \\
\hline
\end{tabular}

Selama penelitian penulis mengajarkan materi matriks dengan model pembelajaran Round Club untuk mengetahui seberapa besar pengaruhnya terhadap kemampuan belajar siswa agar memperoleh hasil yang maksimal.

Data yang telah dikumpulkan dianalisis melalui tes sebelum dan sesudah pelaksanaan model pembelajaran Round Club .Lalu data diolah menggunakan uji statistika. Untuk memudahkan penganalisaan data nilai sebelum pelaksanaan pembelajaran Round Club diberi tanda varabel $X$ dan nilai sesudah pelaksanaan pembelajaran diberi tanda variabel $Y$.

\section{Analisis Data Tes Awal (Pre-test)}

Data nilai pre-test siswa kelas XI IPA 1 SMA Negeri 1 Peusangan Siblah Krueng sebelum menggunakan model pembelajaran Round Club yaitu:

Tabel 3.2. Nilai Tes Awal (Pre-test) Siswa Kelas XI IPA 1

\begin{tabular}{cccc}
\hline No & Nama Inisial & Nilai & $\begin{array}{c}\text { Konversi nilai } \\
\text { dalam 100 }\end{array}$ \\
\hline 1 & AS & 4 & 25
\end{tabular}




\begin{tabular}{|c|c|c|c|}
\hline No & Nama Inisial & Nilai & $\begin{array}{c}\text { Konversi nilai } \\
\text { dalam } 100\end{array}$ \\
\hline 2 & MY & 4 & 25 \\
\hline 3 & MS & 5 & 31 \\
\hline 4 & $\mathrm{CF}$ & 6 & 38 \\
\hline 5 & KY & 6 & 38 \\
\hline 6 & MH & 6 & 38 \\
\hline 7 & $\mathrm{CP}$ & 7 & 44 \\
\hline 8 & RF & 7 & 44 \\
\hline 9 & FM & 7 & 44 \\
\hline 10 & PR & 7 & 44 \\
\hline 11 & MI & 8 & 50 \\
\hline 12 & MY & 8 & 50 \\
\hline 13 & MK & 8 & 50 \\
\hline 14 & $\mathrm{AF}$ & 9 & 56 \\
\hline 15 & IR & 9 & 56 \\
\hline 16 & ZR & 10 & 63 \\
\hline 17 & SQ & 10 & 63 \\
\hline 18 & DA & 10 & 63 \\
\hline 19 & IU & 11 & 69 \\
\hline 20 & NA & 11 & 69 \\
\hline 21 & RR & 11 & 69 \\
\hline 22 & UF & 11 & 69 \\
\hline 23 & IW & 11 & 69 \\
\hline 24 & $\mathrm{RM}$ & 12 & 75 \\
\hline 25 & MA & 12 & 75 \\
\hline 26 & $\mathrm{AL}$ & 13 & 81 \\
\hline 27 & RJ & 13 & 81 \\
\hline 28 & EP & 14 & 88 \\
\hline 29 & UW & 14 & 88 \\
\hline 30 & $\mathrm{FZ}$ & 15 & 94 \\
\hline
\end{tabular}

Berdasarkan tes awal (pre-test) dan saran dari guru maka dibentuk kelompok yang heterogen sebagai berikut:

Tabel 3.3. Nama-Nama Kelompok Diskusi

\begin{tabular}{cll}
\hline No & Kelompok & Inisial Nama \\
\hline 1 & Kelompok 1 & AS, KY, ZR, IW \\
2 & Kelompok 2 & UW, NA, SQ, MY \\
3 & Kelompok 3 & IR, MK, MA, EP \\
4 & Kelompok 4 & UF, DA, RJ, FZ \\
5 & Kelompok 5 & MY, MH, FM, AF \\
6 & Kelompok 6 & MS, RF, MI, RM ,AL \\
7 & Kelompok 7 & CF, CP, PR, IU, RR \\
\hline
\end{tabular}

Analisis Data Tes Akhir (Post-test) Tabel 3.4. Nilai Tes Akhir (Post-test) Siswa Kelas XI IPA 1

\begin{tabular}{cccc}
\hline No & $\begin{array}{c}\text { Nama } \\
\text { Inisial }\end{array}$ & Nilai & $\begin{array}{c}\text { Konversi nilai dalam } \\
\mathbf{1 0 0}\end{array}$ \\
\hline 1 & AS & 7 & 44 \\
2 & MY & 7 & 50 \\
3 & MS & 8 & 50 \\
4 & CF & 9 & 56 \\
5 & KY & 9 & 56 \\
6 & MH & 9 & 56 \\
7 & CP & 10 & 56 \\
8 & RF & 10 & 63 \\
9 & FM & 10 & 63
\end{tabular}

\begin{tabular}{cccc}
\hline No & $\begin{array}{c}\text { Nama } \\
\text { Inisial }\end{array}$ & Nilai & $\begin{array}{c}\text { Konversi nilai dalam } \\
\mathbf{1 0 0}\end{array}$ \\
\hline 10 & PR & 11 & 69 \\
11 & MI & 11 & 69 \\
12 & MY & 11 & 69 \\
13 & MK & 11 & 69 \\
14 & AF & 12 & 75 \\
15 & IR & 12 & 75 \\
16 & ZR & 12 & 75 \\
17 & SQ & 12 & 81 \\
18 & DA & 12 & 81 \\
19 & IU & 13 & 81 \\
20 & NA & 13 & 88 \\
21 & RR & 14 & 88 \\
22 & UF & 14 & 88 \\
23 & IW & 14 & 88 \\
24 & RM & 14 & 88 \\
25 & MA & 14 & 88 \\
26 & AL & 15 & 94 \\
27 & RJ & 15 & 94 \\
28 & EP & 15 & 94 \\
29 & UW & 16 & 100 \\
30 & FZ & 16 & 100 \\
\hline
\end{tabular}

\section{Uji Hipotesis Penelitian (Uji-t)}

Uji hipotesis pada penelitian ini menggunakan statistik uji-t dengan taraf signifikan $\propto=0,05$. Rumusan hipotesis sebagai berikut :

$\mathrm{H} \alpha(\rho \neq 0)$ : Terdapat pengaruh yang signifikan model pembelajaran Round Club pada materi matriks di kelas XI SMA Negeri 1 Peusangan Siblah Krueng.

$\mathrm{H}_{0}(\rho=0)$ : Tidak Terdapat pengaruh yang signifikan model pembelajaran Round Club pada materi matriks di kelas XI SMA Negeri 1 Peusangan Siblah Krueng.

Pada pembelajaran data sebelum dan sesudah disusun dalam bentuk tabel distribusi guna mempermudah untuk mencari korelasi product momen.

\section{Analisis Data Hasil Observasi}

Menurut pengamatan peneliti pada pelaksanaan pembelajaran matematika dengan menggunakan model pembelajaran Round Club telah terlaksana dengan baik, siswa semakin termotivasi dengan aktif dalam kegiatan pembelajaran sehingga tujuan pembelajaran dapat tercapai. 
Pengamatan dilakukan oleh dua orang pengamat dengan mengisi lembar observasi yang telah disediakan sebelumnya dan disesuaikan denga RPP yaitu melaksanakan proses pembelajaran pada materi matriks. Analisis data observasi dengan menggunakan analisis persentase. Skor yang diperoleh masingmasing indikator dijumlahkan dan hasilnya disebut jumlah skor, selanjutnya dihitung persentase nilai rata-rata.

Berdasarkan penelitian yang telah dilaksanakan oleh peneliti, maka dihasilkan skor rata-rata tes awal (pre-test) sebelum menggunakan model pembelajaran Round Club yaitu 59,3 dan tes akhir (post-test) setelah pembelajaran Round Club mempunyai pengaruh yang kuat, dengan nilai skor rata-rata yaitu 75,5 Uji normalitas tes awal diperoleh $x^{2}$ hitung $<x^{2}{ }_{\text {tabel }}$ yaitu $2,67<9,49$ dan uji normalitas tes akhir $x^{2}{ }_{\text {hitung }}<x^{2}{ }_{\text {tabel }}$ yaitu $4,63<9,49$, sehingga dapat disimpulkan bahwa kedua data berdistribusi normal. Begitu juga uji hipotesis. Uji hipotesis dihitung setelah menghitung uji normalitas, karena pada dasarnya salah satu syarat uji hipotesis adalah uji normalitas. Uji hipotesis dengan menggunakan uji korelasi product moment. Dari data statistic yang ada dalam penelitian dan juga dari hasil korelasi didapat $r_{x y}>r_{\text {tabel }}(0,980>0,361)$. Karena harga $r_{x y}>r_{\text {tabel }}$ maka dapat disimpulkan bahwa korelasi antara sebelum dan sesudah pembelajaran Round Club adalah signifikan.

Adapun analisis uji-t dilakukan padaa taraf signifikan $\alpha=0,05$ dan derajat kebebasan untuk daftar distribusi t yaitu $\mathrm{dk}(\mathrm{n}-2)=(30-2)=28$. Adapun kriteria pengujian hipotesis adalah tolah $H_{0}$ jika $t_{\text {hitung }}>t_{\text {tabel }}$ dan terima $\mathrm{H}_{0}$ jika $t_{\text {hitung }}<t_{\text {tabel }}$. Berdasarkan perhitungan yang diperoleh $t_{\text {hitung }}=8,24$, sedangkan harga uji-t menggunakan taraf signifikan $\alpha=0,05$, dengan $\mathrm{dk}=28$ dari tabel distribusi $\mathrm{t}$, diperoleh $t_{\text {tabel }}$ $=2,048$, maka $t_{\text {hitung }}>t_{\text {tabel }}$ yaitu $8,24>$
2,048. Sehingga $H_{0}$ ditolak dan terima $H_{a}$. Dengan demikian dapat disimpulkan bahwa terdapat pengaruh yang signifikan terhadap materi matriks di kelas XI SMA Negeri 1 Peusangan Siblah Krueng.

Hasil observasi aktivitas guru dan siswa pada kedua pembelajaran menunjukkan bahwa ada peningkatan pembelajaran ke taraf yang lebih baik dari pembelajaran pertama ke pembelajaran kedua. persentase rata rata dua orang pengamat aktifitas guru pada pertemuan pertama diperoleh skor rata-rata $91 \%$, hal ini menunjukkan bahwa taraf keberhasilan aktifitas guru pada pertemuan pertama termasuk katagori sangat baik dan untuk pertemuan kedua dengan skor rata-rata $94 \%$, juga merupakan katagori sangat baik. Sedangkan aktifitas siswa pada pertemuan pertama dan kedua memperoleh skor persentase rata-rata sebesar $86 \%$ dan $92 \%$. Hal ini menunjukkan bahwa taraf keberhasilan siswa pada pertemuan pertama termasuk dalam katagori baik dan pada pertemuan kedua termasuk dalam katagori sangat baik.

\section{SIMPULAN}

Beberapa simpulan dari hasil penelitian diatas adalah:

1. Dari hasil pengujian diperoleh nilai $t_{\text {hitung }}>t_{\text {tabel }}$ yaitu $8,24>2,048$. Sehingga dapat disimpulkan bahwa $\mathrm{H}_{0}$ ditolak dan $\mathrm{Ha}_{\mathrm{a}}$ diterima atau dapat dikatakan bahwa terdapat pengaruh yang signifikan model pembelajaran Round Club terhadap materi matriks di kelas XI SMA Negeri 1 Peusangan Siblah Krueng.

2. Hasil observasi aktifitas pembelajaran kelas dengan menggunakan model pembelajaran Round Club yang meliputi aktifitas guru dan siswa pada kedua pembelajaran menunjukkan bahwa ada peningkatan ke taraf lebih baik lagi dari pembelajaran pertama ke peembelajaran kedua. 


\section{DAFTAR PUSTAKA}

Anita, L. (2010). Cooperative Learning. PT Grasindo.

Mulyasa, E. (2007). Menjadi Guru Profesional, Menciptakan Pembelajaran Kreatif dan Menyenangkan (Rosda Kary).

Rahman, R. (2010). Pengaruh Pembelajaran Berbantuan Geogebra Terhadap Kemampuan Berpikir Kreatif Dan SelfConcept Siswa. Universitas Pendidikan Indonesia.

Ramadhani, Fitri ; yanti, O. ; (2017). Penerapan Model Pembelajaran Round Club Terhadap Kemampuan Komunikasi Matematis Siswa. 2(2).
Sugiyono. (2017). MetodePenelitian Kuantitatif, Kualitatif dan R\&D. Bandung: PT Alfabet. In Sugiyono. (2017). MetodePenelitian Kuantitatif, Kualitatif dan R\&D. Bandung: PT Alfabet. https://doi.org/10.1017/CB0978110741532 4.004 